\title{
Storage of Solar Thermal Energy in Borehole Thermal Energy Storage Systems
}

\section{John S. McCartney}

Ning Lu
Tuğçe Başer

Shemin Ge

\author{
Ni Zhan
}

Kathleen Smits

\begin{abstract}
This study focuses on the evaluation of solar thermal energy storage in a medium-scale soil-borehole thermal energy storage (SBTES) system installed in San Diego, CA. The SBTES system consists of an array of thirteen $15 \mathrm{~m}$-deep, closely-spaced borehole heat exchangers installed in conglomerate bedrock. The entire site is above the water table, with relatively dry subsurface conditions. Instrumentation was included into the array to monitor temperature distributions with depth and radial spacing within the array, as well as water content fluctuations near the ground surface. A total of eight evacuated tube solar thermal panels with an absorber area of $4.16 \mathrm{~m}^{2}$ were connected in series to supply heat to a temporary heat storage tank. Results from a 4-month transient heat injection period into the SBTES system are presented in this paper. These include data on the characterization of the thermal properties of the SBTES system, the transient heat flux collected from the solar thermal panels, the corresponding transient heat flux into the subsurface, and the changes in ground temperature.
\end{abstract}

\section{INTRODUCTION}

Soil-borehole thermal energy storage (SBTES) systems are used for storing heat collected from renewable sources in the subsurface that it can be used later for space or water heating. Heat sources such as solar thermal panels generate heat during the day with a greater energy generation during summer months, so SBTES systems permit storage of the abundant and free thermal resource (Sibbitt et al. 2007, McCartney et al. 2013). SBTES systems function in a similar way to geothermal heat exchangers, where a carrier fluid is circulated through a closed-loop pipe network installed in vertical boreholes. Different from conventional geothermal heat exchange systems, the boreholes are spaced relatively close together (1-2 m) to concentrate heat. SBTES systems are a convenient alternative to other energy storage systems as they are relatively inexpensive, involve storage of renewable energy (solar thermal energy), and are space efficient as they are underground (Başer and McCartney 2015).

Since the concept of borehole thermal energy storage systems was introduced by Claesson and Hellström (1981), several SBTES systems have been installed in Canada and Europe that benefit from district-scale heat distribution systems. The Drake Landing SBTES system in Canada provides 95\% of the heat demand of 52 homes (Sibbitt et al. 2007), despite only having an efficiency of heat extraction over heat injection of less than 25\% (Zhang et 
al. 2012). This system supplies heat from solar thermal panels installed on garage roofs to an array of 144 boreholes in a $35 \mathrm{~m}$-deep, 35-m wide grid. Another successful SBTES system was installed in 2007 is in Braedstrup, Denmark (Bjoern 2013). This system supplies heat from $18,000 \mathrm{~m}^{2}$ of solar thermal panels to an array of 50 boreholes having a depth of 47-50 m installed across a $15 \mathrm{~m}$-wide area. This system provides $20 \%$ of the heat to 14000 homes. The most recent SBTES was installed in 2008 in Crailsheim, Germany involving of a series of $55 \mathrm{~m}$-deep boreholes to form a $39000 \mathrm{~m}^{3}$ subsurface storage volume. This system stores heat from $7410 \mathrm{~m}^{2}$ of flat plate solar thermal collectors to provide heat for a school and 230 dwellings (Nussbicker-Lux 2012).

Despite the successful use of SBTES systems in practice, there are still opportunities for geotechnical engineers to help understand and improve the efficiency considering the hydrogeological setting of these systems. This is the focus of a collaborative NSF project between the University of California San Diego (UCSD), University of Colorado Boulder, and Colorado School of Mines. In particular, this study seeks to understand the benefits of installing SBTES systems in the vadose zone, the layer of partially-saturated soil or rock near the ground surface extending up to depths on the order of 10 of meters in some locations. The unsaturated porous material in the vadose zone has a lower apparent thermal conductivity that limits the loss of heat from the subsurface heat storage system, yet still permits large amounts of heat to be stored due to the combination of a reasonably high volumetric heat capacity and a large storage volume. In addition to coupling between thermal and hydraulic properties of unsaturated soils the modes of heat transfer in unsaturated soils may include a combination of conduction and convection due to the flow of pore water in liquid and vapor forms under thermal gradients.

This project focuses on the development of new coupled constitutive equations for the thermo-hydraulic properties of soils (Lu and Dong 2015) as well as numerical efforts to understand the impacts of borehole array geometry, ground properties, heat injection magnitudes, and heat injection duration on the heat storage (Başer et al. 2015), characterize the behavior of borehole system behavior (Başer et al. 2016a), understand the impacts of different modes of heat transfer (Başer et al. 2016b, 2016c), and understand the role of incorporating a thermal insulation layer (Başer et al. 2016d). However, data from a field-scale installation is still necessary to understand the variable boundary conditions for heat injection, to provide a baseline data set for calibration of numerical simulations, and to assess different injection schemes to improve the efficiency of heat storage. These are the objectives of a new field installation at UCSD described in this update, which has recently gone into operation.

\section{SBTES SYSTEM AT UCSD}

\section{Site Description}

The full-scale SBTES system was installed at the Englekirk Structural Engineering Center (ESEC) on the UCSD campus. The subsurface at the site consists of $1 \mathrm{~m}$ of silty sand underlain by conglomerate bedrock, with a groundwater table more than $30 \mathrm{~m}$ deep. The thermal conductivity of the unsaturated colluvium measured using the TRIM method (Lu and Dong 2015) and was found to be $0.5 \mathrm{~W} / \mathrm{mK}$ for the average degree of saturation with depth. The conglomerate has a relatively high hydraulic conductivity of approximately $10-5 \mathrm{~m} / \mathrm{s}$, indicating that infiltration and thermally induced water flow may affect heat transfer processes. The SBTES system includes a network of 25 mm-diameter high density polyethylene (HDPE) tubing installed within 15 boreholes in a hexagonal array with a spacing of $1.5 \mathrm{~m}$ as shown in Figure 1. Although the number of boreholes is much smaller than those incorporated into the district-scale heating systems mentioned above, it provides an important data point in the scaling of SBTES systems for different sizes of communities. 


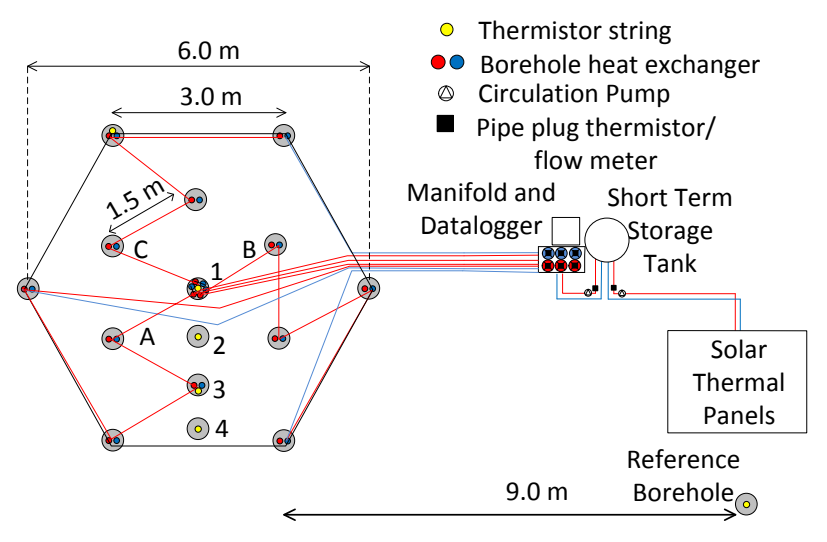

(a)

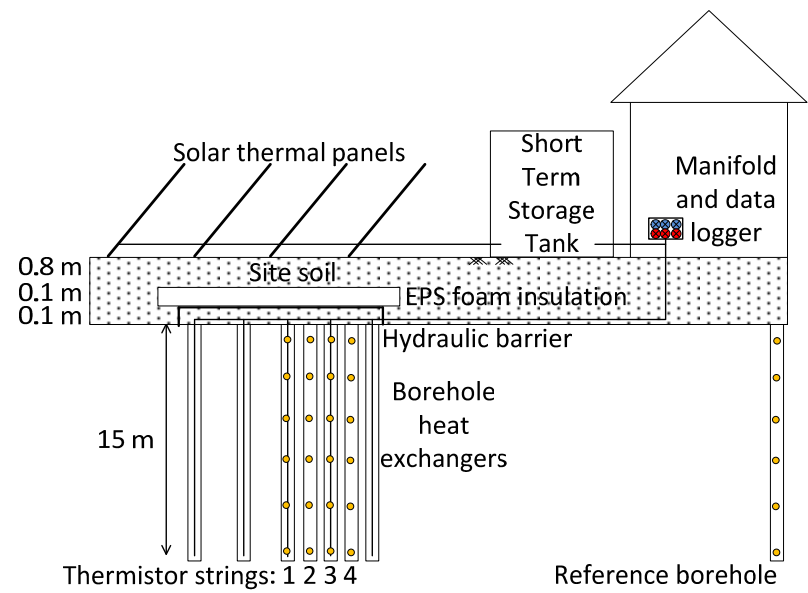

(b)

Figure 1 UCSD SBTES system: (a) Plan view, (b) Elevation view

Three heat exchange loops (A, B, C) were installed in the array so that heat could be injected first into the center of the array then split into three directions to ensure uniform distribution of heat to the different parts of the array (as opposed to connecting all of the heat exchangers in series) and to lead to a radial stratification of heat from the center. Thermistor strings having 6 thermistors equally spaced along a single cable were installed in four boreholes within the array (labeled 1 to 4 ) as well as in a reference borehole approximately $9 \mathrm{~m}$ outside of the array. These sensors permit evaluation of the transient heat transfer within the array as well as the undisturbed ground temperature fluctuations with depth outside of the array over time. Other instrumentation include dielectric sensors in the soil near the ground surface to monitor infiltration and evaporation, thermocouples to monitor the temperature of the carrier fluid entering and exiting the boreholes, flow meters to measure the fluid flow in each loop, and a temperaturehumidity sensor to monitor ambient air conditions.

\section{Construction Process}

The slurry method was used to drill the $100 \mathrm{~mm}$-diameter boreholes as shown in Figure 2(a). Care was taken during drilling due to the relatively small borehole spacing of $1.5 \mathrm{~m}$. Heat exchange tubing and thermistor cables were inserted into the open boreholes and a mixture of sand-bentonite grout placed with a tremie into the boreholes. The soil was then excavated in a hexagonal shape around the array to a depth of $1 \mathrm{~m}$, as shown in Figure 2(b). A $2 \mathrm{~mm}-$ thick hydraulic barrier was placed over the array after placement of a thin layer of site soil for leveling, as shown in Figure 2(c). To prevent heat loss to the atmosphere a layer of expanded polystyrene (EPS) insulation was placed on top of the array as shown in Figure 2(d) and the excavation was backfilled with compacted site soil.

Eight evacuated tube solar thermal collectors having a total area of $33 \mathrm{~m}^{2}$ were used to collect heat from the sun, and are shown in Figure 3(a). A 2400 liter water-filled tank is used to store heat from the solar panels on a shortterm basis to extend the time for injection of the heat collected from the solar thermal panels into the subsurface. The tank included two copper heat exchangers, one connected to the solar thermal connectors and the other connected to the borehole array. The heat transfer through the various components of the system is controlled using the manifold and solar pump station shown in Figure 3(b). 


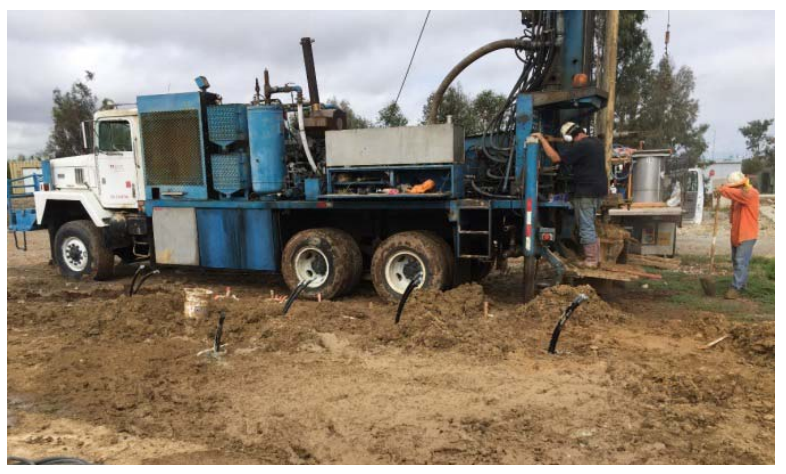

(a)

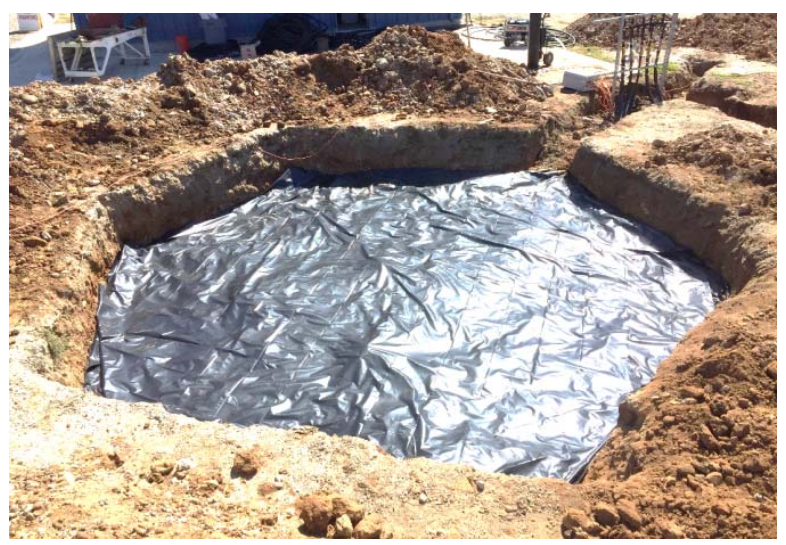

(c)

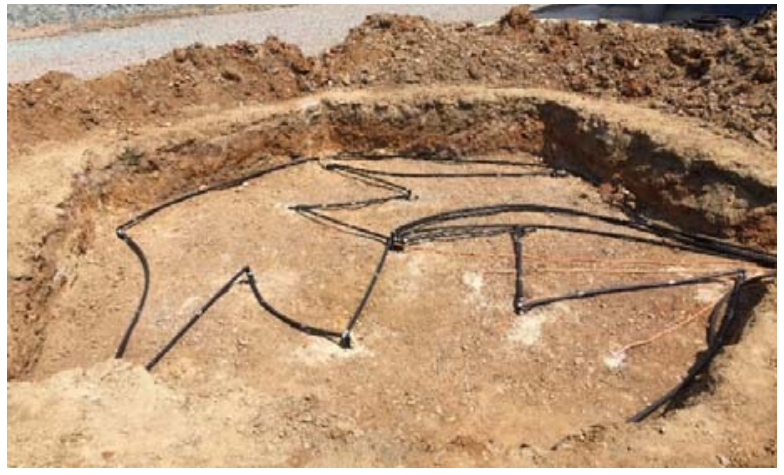

(b)

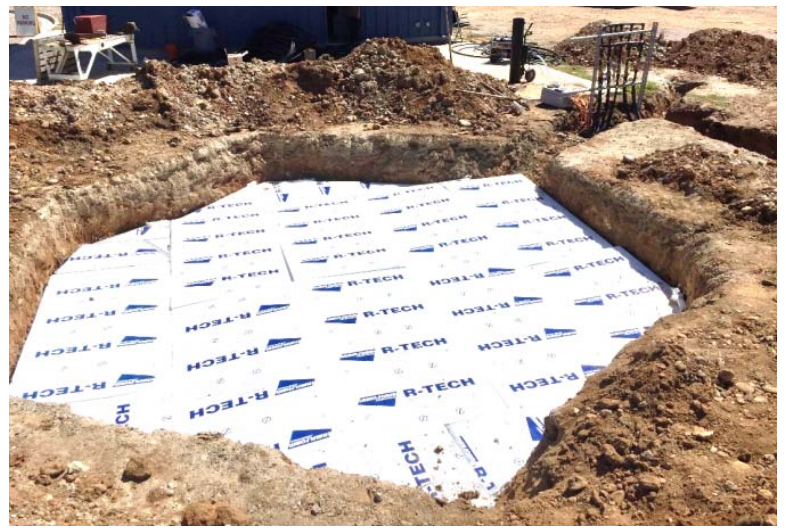

(d)

Figure 2 Pictures of the SBTES installation at UCSD: (a) Drilling; (b) Borehole heat exchangers connected after excavation of $1 \mathrm{~m}$ of surface soil; (c) Hydraulic barrier; (d) Thermal insulation layer

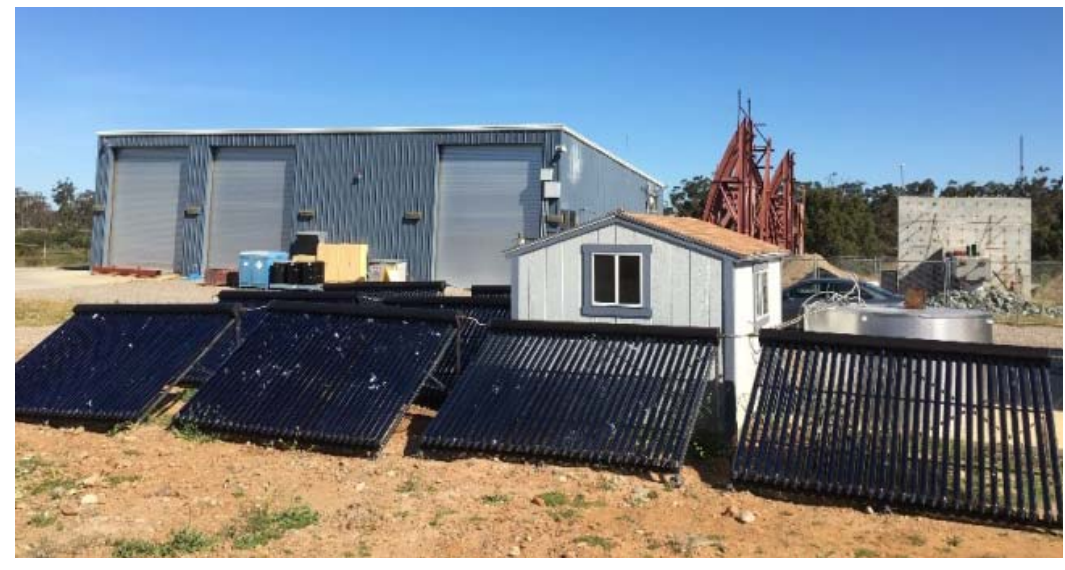

(a)

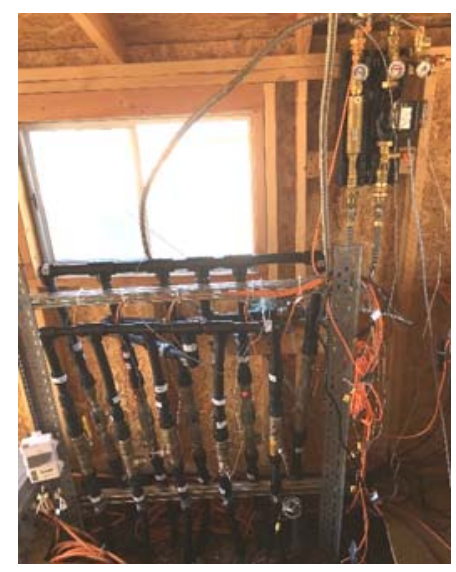

(b)

Figure 3 SBTES system components at the ground surface: (a) Solar thermal panels; (b) Geothermal manifold 


\section{PRELIMINARY DATA ANALYSIS}

A preliminary operation stage of the system was started on April 29th, 2016, with the goal of characterizing the typical heat transfer from the various components as well as the thermal characterization of the subsurface. The operations are still preliminary because a control system has not yet been implemented to ensure that heat is only collected from the solar thermal panels during the day. Specifically, the circulation pumps in the geothermal and solar loops are operated continuously. Accordingly, fluid is still circulated through the solar panels at night, which may result in a slight loss in heat from the system. Nonetheless, because the nights in San Diego are very mild a significant amount of heat loss has not been detected. Further, the optimal configuration of the solar thermal panels is still being investigated. The heat transfer in the different components of the system can be calculated from the entering and exiting carrier fluid temperatures, the carrier fluid flow rate, and the carrier fluid (water) properties, as follows:

$$
\dot{Q}=\dot{V}_{f} \rho_{f} C_{f}\left(T_{\text {in }}-T_{\text {out }}\right)
$$

where $\dot{V}_{f}$ is the measured volumetric flow rate of the heat exchanger fluid (water), $\rho_{\mathrm{f}}$ is the density of water (1000 $\left.\mathrm{kgm}^{-3}\right), \mathrm{C}_{\mathrm{f}}$ is the specific heat capacity of water $\left(4183 \mathrm{Jkg}^{-1} \mathrm{~K}^{-1}\right)$, and $\mathrm{T}_{\text {in }}$ and $\mathrm{T}_{\text {out }}$ are the measured temperatures of the water entering and exiting the heat exchanger loops, respectively. The heat transfer rate collected from the solar thermal panels and injected into the borehole array is shown in Figure 4(a). The heat transfer rate from the solar thermal panels fluctuates in a similar manner to the air temperature shown in Figure 4(b). The average heat transfer rate collected from the solar thermal panels is $5010 \mathrm{~W}$, with a standard deviation of $5996 \mathrm{~W}$. Much higher values than the average value were noted in the peak sunlight times in the afternoon, and the lowest value was still greater than zero. These peak values correspond to a peak fluid temperature of nearly $90{ }^{\circ} \mathrm{C}$ on most days, which is why solar thermal panels are used frequently for hot water generation in homes.

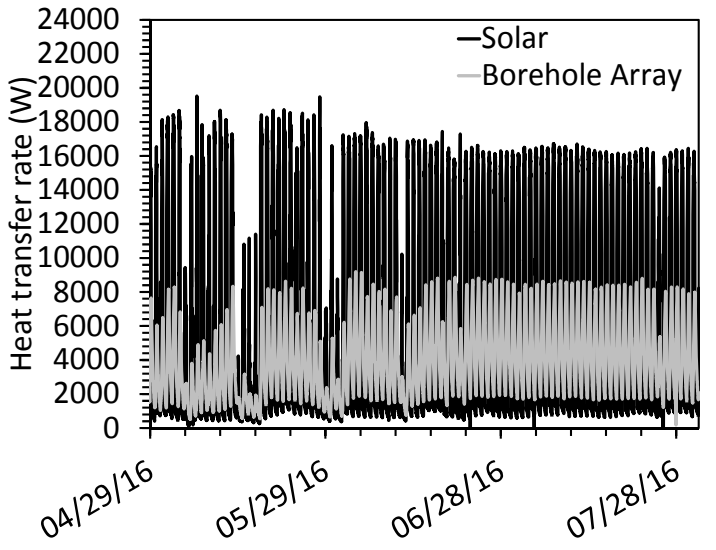

(a)

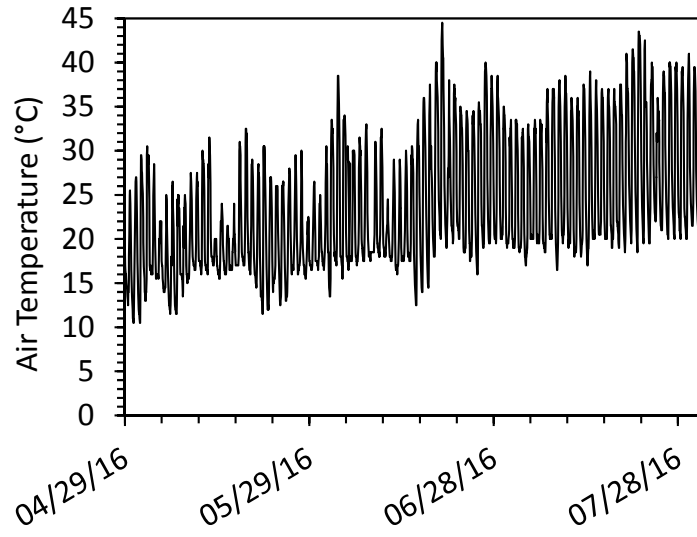

(b)

Figure 4 (a) Heat transfer from the solar thermal panels and into the borehole array; (b) Outside air temperature

The average heat transfer rate into the borehole array is $3182 \mathrm{~W}$ with a standard deviation of $2073 \mathrm{~W}$. Due to the short term storage tank, the heat transfer rate into the borehole array exceeded that collected from the solar thermal panels for several hours. As there is $196 \mathrm{~m}$ of geothermal heat exchanger boreholes in the SBTES system, the average heat transfer rate per unit meter is $16 \mathrm{~W} / \mathrm{m}$, while the maximum value is $44 \mathrm{~W} / \mathrm{m}$. The typical heat transfer 
rate per unit meter observed in the district-scale SBTES systems mentioned above is $30 \mathrm{~W} / \mathrm{m}$, so the range of heat transfer rates encountered at this site is reasonable. The cumulative thermal energy collected and injected during this time period is shown in Figure 5(a). The efficiency of heat injection, defined as the heat injected over that collected, is shown in Figure 5(b) and has stabilized at approximately 0.7. This may be improved by adding a control system for the solar thermal panels so that they only circulate fluid during the day, reconfiguring the panels (connection in parallel instead of in series), and changing the fluid flow rates in the solar thermal panels and in the geothermal heat exchangers. The analyses of Başer and McCartney (2015) indicate that some of the heat injected into the array will be lost due to diffusion to the surrounding subsurface, so the amount of heat injected will not equal the heat stored. The heat loss is currently being evaluated using numerical simulations of this array.

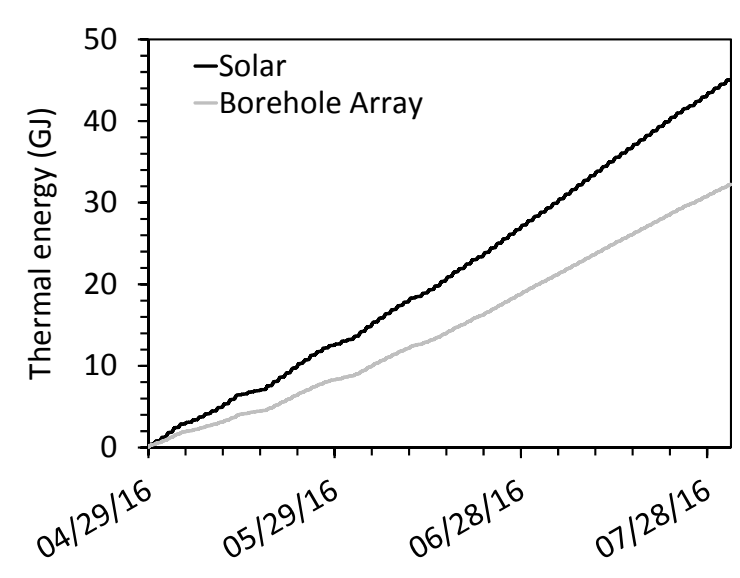

(a)

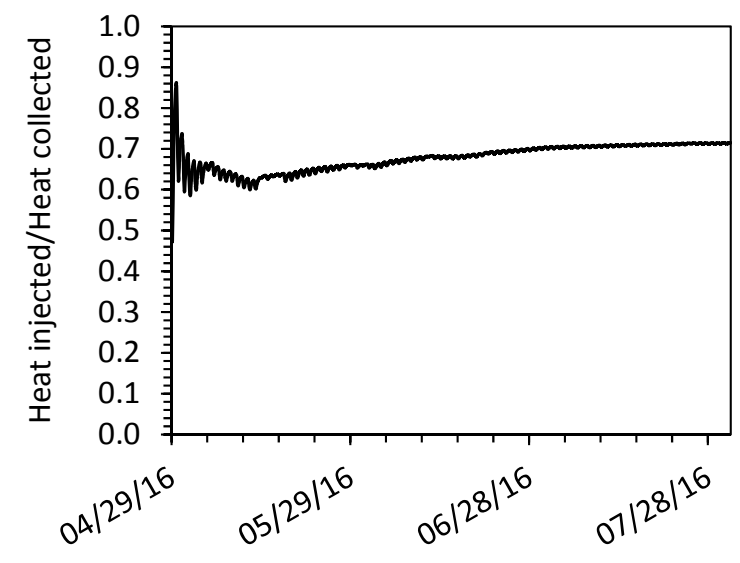

(b)

Figure 5 (a) Comparison of thermal energy collected from the solar thermal panels and injected in the borehole array; (b) Efficiency of heat injection

The analyses presented so far in Figures 4 and 5 are relevant to characterizing the boundary conditions for heat transfer into SBTES systems, and are important in the simulation of the SBTES systems using heat transfer software. Some of the preliminary ground temperatures at a depth of $9.29 \mathrm{~m}$ at different locations from the center of the array are shown in Figure 6. The temperatures at the locations of the heat exchangers increase nonlinearly with time, with daily fluctuations in temperature. The temperatures of the soil at the locations between the heat exchangers increase without daily fluctuations. The temperature of the soil in the reference borehole has actually slightly decreased at this depth over the time period of the evaluation. Overall, the duration of time required to heat the soil is slow, but this is similar to observations from Drake Landing, which required several years to become fully charged (Zhang et al. 2012).

The ground temperatures with depth shown in Figure 7(a) indicate that the ground temperature is slowly increasing above the ambient ground temperature shown in Figure 7(b). The higher temperatures near the surface are likely due to surface effects, while the lower temperatures at the base are due to downward heat loss. Although the average change in the temperature of the ground is only $5{ }^{\circ} \mathrm{C}$, this represents a significant amount of thermal energy over the volume of the array. A portion of this energy will be lost to the surrounding subsurface, but as the size of the array is large, it represents a significant amount of energy. 


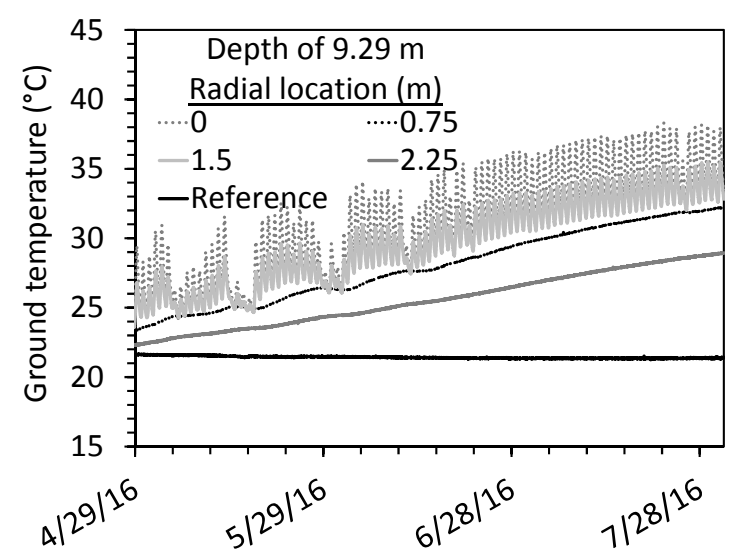

Figure 6 Ground temperatures at different radial locations from the center of the array at a depth of $9.29 \mathrm{~m}$

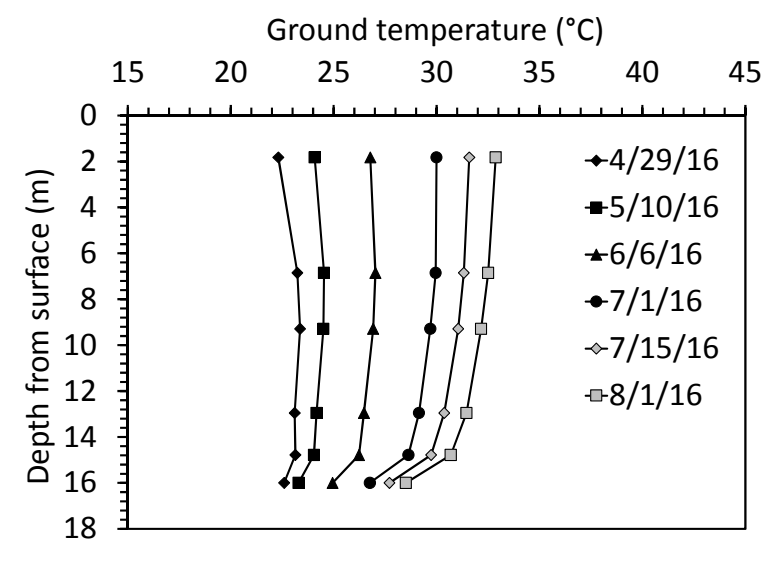

(a)

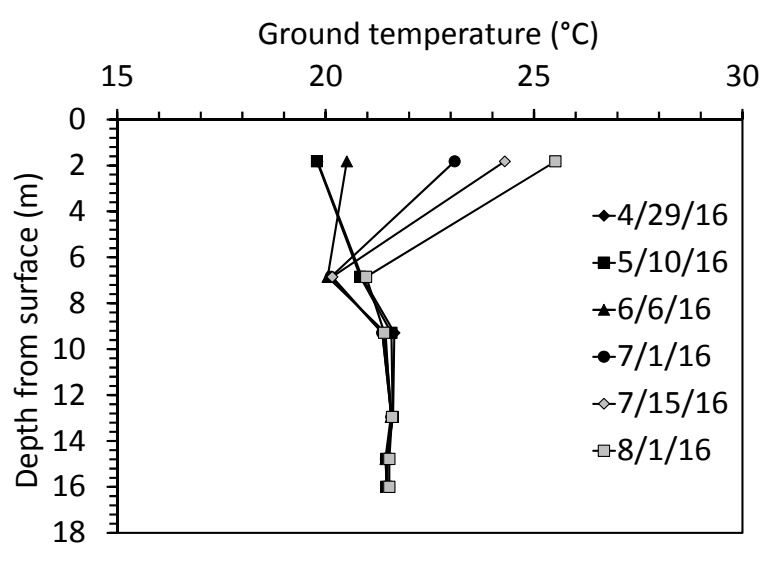

(b)

Figure 7 Ground temperatures: (a) Borehole 2 within the array; (b) Reference borehole outside of the array

\section{CONCLUSION}

This paper shows some of the preliminary data from a full-scale soil-borehole thermal energy storage (SBTES) system constructed at the University of California San Diego. Data on the solar thermal energy collectors and borehole heat exchangers indicates that $70 \%$ of the solar thermal energy collected has been injected into the subsurface. This number is lower than desired but can be improved by refining the details of the heat injection scheme. The ground temperatures over a 4 month period have increased by approximately $10{ }^{\circ} \mathrm{C}$. This increase in temperature may appear to be small, but it represents a significant thermal energy magnitude of $30 \mathrm{GJ}$ transferred into a large volume of soil. The results from this site will be further analyzed using numerical simulations to evaluate the heat losses from the array, as well as strategies to optimize the heat injection scheme to optimize the heat injection. 


\section{ACKNOWLEDGEMENTS}

Funding from NSF 1230237 is appreciated. The opinions are those of the authors alone.

\section{NOMENCLATURE}

$$
\begin{aligned}
\dot{Q} & =\text { Heat transfer rate }(\mathrm{W}) \\
\dot{V} & =\text { Volumetric flow rate of fluid } \\
\rho & =\text { Density }\left(\mathrm{kgm}^{-3}\right) \\
\mathrm{C} & =\text { Specific heat capacity }\left(\mathrm{Jkg}^{-1} \mathrm{~K}^{-1}\right) \\
\mathrm{T} & =\text { temperature of fluid }(\mathrm{K})
\end{aligned}
$$

\section{Subscripts}

$$
\begin{aligned}
f & =\text { fluid } \\
\text { in } & =\text { inlet fluid } \\
\text { out } & =\text { outlet fluid }
\end{aligned}
$$

\section{REFERENCES}

Başer, T. and McCartney, J.S. 2015. Development of a full-scale soil-borehole thermal energy storage system. Proc. Int. Foundation Conference and Equipment Exposition (IFCEE 2015). ASCE. Pp. 1608-1617.

Başer, T., Lu, N., and McCartney, J.S. 2016a. Operational response of a soil-borehole thermal energy storage system. ASCE Journal of Geotechnical and Geoenvironmental Engineering. 04015097-1-12. 10.1061/(ASCE)GT.1943-5606.0001432.

Basser, T., Dong, Y., and McCartney, J.S. 2016b. Heat content in soil-borehole thermal energy systems in the vadose zone. ICEGT 2016: 1st International Conference on Energy Geotechnics. Kiel. Aug. 29-31. 1-8.

Başer, T., Dong, Y., Lu, N., and McCartney, J.S. 2016c. Role of considering non-constant soil thermal parameters in the simulation of geothermal heat storage systems in the vadose zone. 8th Asian Young Geotechnical Engineers Conference 2016 (AYGEC 2016). Astana, Kazakhstan. 1-6.

Başer, T., McCartney, J.S., Moradi, A., Smits, K., and Lu, N. 2016d. Effect of a thermo-hydraulic insulating layer on the long-term response of soil-borehole thermal energy storage systems. GeoChicago 2016: Sustainability, Energy and the Geoenvironment. Chicago. Aug. 14-18. pp. 1-10.

Bjoern, H. 2013. Borehole thermal energy storage in combination with district heating. EGC 2013. Pisa. June 3-7. 1-13.

Claesson, J., and Hellström, G. 1981. Model studies of duct storage systems. New energy conservation technologies and their commercialization. J. P. Millhone and E. H. Willis, eds., Springer, Berlin. 762-778.

Lu, N. and Dong, Y. 2015. A closed form equation for thermal conductivity of unsaturated soils at room temperature. Journal of Geotechnical and Geoenvironmental Engineering. 141(6), 04015016.

McCartney, J.S., Ge, S., Reed, A., Lu, N., \& Smits, K. 2013. Soil-borehole thermal energy storage systems for district heating. EGC 2013. Pisa. Jun. 3-7. 1-10.

Nussbicker-Lux, J. 2012. The BTES project in Crailsheim (Germany) - Monitoring results. Proc. of 12th International conference on Energy Storage- Innostock, 16-18 May, Lleida, Spain.

Sibbitt, B., Onno, T., McClenahan, D., Thornton, J., Brunger, J., and Wong, B. 2007. The Drake Landing solar community project - Early results. Canadian Solar Buildings Conference, Calgary. Jun. 10-14. 1-8.

Zhang, R., Lu, N., and Wu, Y. 2012. Efficiency of a community-scale borehole thermal energy storage technique for solar thermal energy. GeoCongress 2012, ASCE, Reston, VA, 4386-4395. 